\title{
The Psychology, Geography, and Architecture of Horror: How Places Creep Us Out
}

\author{
Francis T. McAndrew
}

\begin{abstract}
Why do some types of settings and some combinations of sensory information induce a sense of dread in humans? This article brings empirical evidence from psychological research to bear on the experience of horror, and explains why the tried-and-true horror devices intuitively employed by writers and filmmakers work so well. Natural selection has favored individuals who gravitated toward environments containing the "right" physical and psychological features and avoided those which posed a threat. Places that contain a bad mix of these features induce unpleasant feelings of dread and fear, and therefore have become important ingredients of the settings for horror fiction and films. This article applies McAndrew and Koehnke's (2016) theory of creepiness to the study of classic horror settings and explores the role played by architecture, isolation, association with death, and other environmental qualities in the experience of creepiness and dread.
\end{abstract}

Keywords: horror, architecture, ghosts, haunted houses, paranormal experiences, environmental psychology, evolutionary psychology

Scholars in a range of academic disciplines including philosophy (Bachelard 1964), geography (Tuan 1974, 1977), and psychology (Sommer 1969; Proshansky, Fabian, and Kaminoff 1983) have long recognized the importance of "place" in human experience. Our daily physical surroundings play an important role in creating order, meaning, and stability in our lives, and the cultural rituals that make up the very fabric of social and religious life have historically been inseparable from the physical spaces in which they transpire (Smith 1987; Martin 2014). In short, a sense of the place we live is closely related to our personal identity since so much of who we are depends upon where we live and the experiences that we have had there (Dovey 1985; McAndrew 1998).

But what happens when the physical space around us creates feelings of disorientation and dread rather than feelings of comfort, predictability, and security?
Although other scholars have reflected on this question by examining the role played by the settings and ambient sensation in horror fiction and film, especially when the story grows out of the Gothic tradition (Botting 2015; Brown 2016; Bussing 2016), they have typically not taken advantage of recent research on evolved psychology to make sense of their findings. These literary analyses focus on fictional spaces, but I contend that fictional spaces are effective precisely because they accurately, albeit in a somewhat exaggerated fashion, reflect the components of real physical spaces that cause people to feel uneasy.

It is the goal of this paper to apply what psychologists and other scientists have learned about human emotional responses to physical surroundings to understanding why some settings and some combinations of sensory information can induce a sense of horror in humans. The hoped-for contribution is to bring empirical 
evidence from psychological research to bear on the experience of horror, and to explain why the tried-and-true horror devices intuitively employed by writers and filmmakers work so well.

The unifying thesis of the article is that places that inspire feelings of creepiness and horror possess combinations of features that humans have evolved to regard with caution, either because such features were associated with the presence of predators or other natural hazards, or because they confront us with limited sensory information and a lack of freedom of movement and control which would impair our ability to deal with an emergent threat.

We shall begin with a discussion of how humans have been programmed through evolution to respond emotionally to their physical surroundings, and how some emotional experiences, such as creepiness and horror, are related to "agent detection" mechanisms that have evolved to protect us from predators and enemies. The paper will then explore how factors such as social isolation and associations of places with death or other troubling events can prime the type of thinking that exacerbates the experience of horror inherent in the geography or architecture of a setting.

\section{We Are Programmed to Respond Emotionally to Our Physical Surroundings}

It is well established that the environmental preferences of animals are under genetic control (Alcock 1993), and to some extent this appears to be true for humans as well. Research by environmental psychologists has confirmed that the most attractive natural environments contain things such as running water and open meadows surrounded by woods, the very features that would have been beneficial for the survival of early humans (Kaplan 1987). In other words, people who were drawn to the "right" places did better than those who were not, and over time their genes were favored over those of individuals who spent too much time in sparser, more barren landscapes.
But places exhibit more abstract evolutionarily relevant features as well, and it turns out that being drawn to the "right" abstract features of places may have been just as important for our ancestors' survival. McAndrew (1993) has referred to such environmental features as psychological features, and places that lack the right psychological features set off our creep detectors.

British geographer Jay Appleton (1975) was the first to describe two qualities of physical space that determine whether a place is attractive or frightening to humans: "Prospect" and "Refuge." Refuge means having a secure, protected place to hide where one can be sheltered from danger, while prospect refers to one's clear, unobstructed view of the landscape. Attractive places offer us a lot of prospect and a lot of refuge, or what landscape architect Randolph Hester (1979) refers to as a "Womb with a View."

Our love of such spaces shows up everywhere. Universally, children love playing in enclosed spaces such as cardboard boxes, tree houses, and in bushes or other dense vegetation where they feel hidden; the concepts of prospect and refuge may help explain the almost magical quality of the feelings evoked by memories of favorite childhood hiding places and the richness of detail that can often be recalled about them decades later. Similarly, diners in restaurants usually prefer to occupy tables in corners or nooks, especially when these locations allow them to sit with their backs against a wall, and they will usually only settle for tables in the center of the room when all of the more desirable seats have been taken (McAndrew 1993).

In the words of Appleton, we love the feel of these spaces because they are, evolutionarily speaking, places where "you can see without being seen, and eat without being eaten" (Greenbie 1982, 2).

The optimal environment for human comfort is one that offers a lot of prospect and refuge for the individual; the worst combination is very little prospect or refuge for the individual. Research has confirmed that places that offer bad combinations of prospect and refuge for us are 
perceived as unsafe and dangerous (Fisher and Nasar 1992), also because they may offer a lot of hiding places for people or things that may intend to do us harm.

Scary places may also lack what environmental psychologists refer to as "legibility." Legibility reflects the ease with which a place can be recognized, organized into a pattern and recalled-in other words, a place that we can wander around in without getting lost (McAndrew 1993).

More legible places are usually preferred over less legible ones, but if we feel assured that a place is not dangerous, a dose of illegibility can actually enhance the attractiveness of a place to us; this property has been referred to as "mystery." Mystery implies that the place contains more information than can be seen at the moment, and that one could learn much about it by walking through it and exploring. The strategic use of mystery has been used to great effect by landscape architects in settings such as Japanese gardens (Eliovson 1978). Many studies have confirmed that people do in fact perceive mystery as a distinct quality of landscapes and that a sense of mystery can increase the attractiveness of natural environments (Kaplan and Kaplan 1989). However, when a heightened sense of mystery is accompanied by a sense of potential danger, as it is in deep narrow canyons, dark urban alleys, and houses thought to be haunted, mystery decreases the attractiveness of the place (Herzog 1987; Herzog and Smith 1988).

It is not only the psychological features of places that can make them good settings for horror. Physical features that posed a threat to our ancestors can easily become creepy, even if they have other qualities that make them beneficial to us; water is a perfect example of an indispensable and usually attractive element of a natural setting that is frequently associated with horror. Rivers, lakes, and ponds often provide the setting for horror stories about ghosts. This makes sense in that deep water has always posed a hazard to humans and drowning is a common cause of human death, both accidental and intentional. It is therefore not very surprising to find that bodies of water are frequently linked with paranormal experiences, as in the stories of haunted highways, ponds, wells, ships, and bridges detailed by Davies (2007) and Nickell (2012).

The kinds of places described above can evoke feelings of fear, horror, and being creeped out. It may be useful to think of these three related emotions as different stages of the same experience. Getting creeped out is an unpleasant state of heightened vigilance in which we grapple with ambiguity in our immediate situation. We are not sure if there is an actual danger or threat to be wary of, but the lack of clarity focuses our attention as we deal with the felt urgency of resolving the ambiguity so that we know how to proceed. Horror, on the other hand, is the growing awareness that we are indeed facing some sort of danger, although we may not yet exactly understand the nature of the threat or how best to deal with it. Fear is the clearest of the three emotions. It occurs when we clearly recognize the nature of the danger that we face and we concoct a strategy for dealing with it.

Throughout this paper, the focus will remain firmly fixed on the frightening, negative experience of horror, but it must be acknowledged that under some circumstances creepiness and horror can be seductive (Clasen 2017), as evidenced by the sums of money we spend each year on horror movies and commercial haunted houses. Clearly, for many people, the creepy can have a peculiar "allure."

How could such things possibly be entertaining to us?

I propose that our enjoyment of haunted houses and horror movies taps into the same evolved psychological mechanisms that exist to help us learn from the experiences of others (De Backer, Nelissen, Vyncke, Braeckman, and McAndrew 2007). In the safety of a movie theater or amusement park, watching other individuals deal with serial killers, zombies, or other paranormal threats gives us the chance to 
mentally rehearse strategies that we might use if we would ever find ourselves in a similar situation (Clasen, Kjeldgaard-Christiansen, and Johnson 2018).

So, yes, horror can be fun if it is not the real thing. Having said this, the rest of this article will concern itself with the less fun stuff.

\section{On the Nature of Creepiness}

The "threat ambiguity theory" (Smith 2016), proposed by McAndrew and Koehnke (2016), helps shed light on why some people appear creepy to us. McAndrew and Koehnke tested their theory by way of an online survey of 1,341 individuals (1,029 females, 312 males) ranging in age from 18 to 77 with a mean age of 28.97. The researchers did not ask participants to report their country of origin, but they reported that an unrelated study using an identical recruitment strategy yielded respondents from 54 different nations, although Americans were by far the largest group. In the first section of the survey, participants rated the likelihood that a hypothetical "creepy person" would exhibit 44 different behaviors, such as unusual patterns of eye contact or physical characteristics like visible tattoos. In the second section of the survey, participants rated the creepiness of 21 different occupations, and in the third section, they simply listed two hobbies that they thought were creepy. In the final section, participants expressed their level of agreement with 15 statements about the nature of creepy people.

The results of the study were consistent with the idea that creepiness is a response to the ambiguity of threat. Nonnormative nonverbal, and emotional behaviors, unusual physical characteristics and hobbies, or suspect occupations set off our "creepiness detectors." Men were more likely to be perceived as creepy by males and females alike, and women were more likely to perceive sexual threat from creepy people.

Thus, we get creeped out by certain people because they behave in bizarre and unpredictable ways, violating the subtle social conventions that enable us to understand their intentions; this makes it difficult for us to know what to expect when we encounter them. In other words, they present us with an ambiguity as to whether or not they are someone to fear, and this ambiguity makes us very uncomfortable.

McAndrew and Koehnke's theory received support in two experiments conducted by Watt, Maitland, and Gallagher (2017). In the Watt et al. studies, people rated faces on creepiness, trustworthiness, and attractiveness, gave detailed reports of specific creepy encounters they had experienced, and described what they believed a prototypical creepy individual would look like. Their results confirmed that men are more likely to be perceived as creepy than women and that uncertainty about whether the person was trustworthy or not was a key ingredient. They also confirmed that physical characteristics such as an unusually lean body type and unusual facial features, especially in the region of the eyes or teeth, predisposed their participants toward making a judgment of creepiness. Watt and her colleagues noted the quick, nonconscious way by which judgments of creepiness occurred, indicating that such judgments are intuitive and rely on emotional reasoning rather than deliberative detailed cognitive analysis.

I propose that places can creep us out for the very same reasons that people can, by presenting us with ambiguous information that makes it unclear if the place poses a threat to us or not. Places can have this effect on us because they activate an evolved psychological adaptation known as an "agent detection mechanism."

\section{Agent Detection Mechanisms}

Agent detection mechanisms (Atran 2002; Barrett 2005) are processes that have evolved to protect us from harm at the hands of predators and enemies. If you're walking through the woods alone at night and hear the sound of something rustling in the bushes, you will respond with a heightened level of arousal and 
attention. You will behave as if there is a willful "agent" present who is about to do you harm. If it turns out to be a gust of wind or a stray cat, you lose little by overreacting. But if you fail to activate the alarm response and a true threat is present-well, the cost of your miscalculation could be high.

The evolutionary precursors of human agent detection mechanisms can be found throughout the animal kingdom, and the most relevant of these are evolved responses to predators and to the environments that harbor them. Laboratory rats that have never experienced a natural environment walk along walls within large enclosures as an adaptation to ancestral airborne predators such as hawks and owls, and virtually all primates have an aversion to sleeping on the ground where they might easily be found by predators such as large cats or snakes (Busse 1982; Isbell 1994; Ramakrishnan and Coss 2000). Isolated populations of prey animals such as Sitka black-tailed deer (Le Saout et al. 2015), rodents (Orrock 2010), and Père David's Deer (Li et al. 2011) that have been free of predation for dozens of generations typically display enhanced vigilance and tension in response to environments and stimuli associated with ancestral predators; this is a testament to the genetic durability of these adaptations.

Vestiges of such responses have been documented in human children who intuitively understand which environmental affordances offer the best hiding places from predators (Coss and Moore 2002; Coss and Penkunas 2016) and who prefer sleeping arrangements that minimize fears of things lurking beneath them (Spörrle and Stich 2010).

So, horror "primes" our agent detection mechanisms and triggers a search for predators. Most horror films exploit this human predilection by making the audience squirm over the uncertainty of whether there is a demon in the house in The Exorcist, whether the hotel in The Shining is truly haunted, or whether there is really anything to fear in the woods in The Blair Witch Project, to cite a few examples.

\section{Places Are Scarier When We Are Isolated and Alone}

Humans are a highly social species with a strong need for interaction with others, especially during times of stress; when we go through a trying ordeal alone, a lack of emotional support and comradeship can increase our anxiety and hinder our ability to cope. We rely on others to help us resolve ambiguity, and we rely on them for cooperative defense against threat. It is therefore reasonable to expect that most people have an aversion to being alone for extended periods of time, especially in uncertain environments. Therefore, everything seems creepier to us when we are alone.

Horror writer Stephen King was once asked after a lecture that I attended in 1979 if he believed in ghosts and the other paranormal things that he wrote about. He responded "no," but then quickly added that when he "was alone, late at night, yes, always."

The tendency of isolation to amplify creepiness is forcefully driven home in the film Shut-In (Blackburn 2016). Naomi Watts plays a widowed child psychologist who lives in isolation in rural New England with her son, who is comatose and bedridden as the result of an automobile accident. Snowed in and cut off from the outside world, Watts' character descends into a desperate existence. It soon becomes difficult for her to distinguish the phantasms of her imagination from the reality of the creepy goings-on in her apparently haunted house.

Shut-In, of course, is not the first movie to use isolation as a vehicle for madness (Clasen 2017). The characters played by Jack Nicholson in The Shining (Kubrick 1980) and Tom Hanks in Cast Away (Zemeckis 2000) found themselves in similar predicaments. Although movies like Shut-In are fictional, the toll on the protagonist's psyche from being so alone for so long is based on the science of social isolation.

When we are alone in an unusual environment, the way in which we process sensory information can change (Suedfeld 1987). For 
example, we normally spend most of our time attending to and processing external stimuli from the physical world around us. However, monotonous or tedious stimulation from our surroundings may cause us to turn our attention inward-within ourselves-which most of us have much less experience handling.

This may lead us to lose confidence in our understanding of what's going on in our surroundings; is that creaking sound upstairs just an old house pushing back against the wind, or is it something more sinister? When we're uncertain, the first thing we usually do is to look to the reactions of others to figure out what is going on. Without others with whom to share information and reactions, ambiguity becomes very hard to resolve. When this happens, our mind may quickly race to the darkest possible conclusions.

Hence, it is no accident that the prototypical Hollywood haunted house is in a remote, isolated location, far removed from the rest of society (think of the off-season resort hotel in The Shining, for example). If bad things do happen, help would be a long time coming, even if communication with the outside world were possible. And conveniently, in old horror movies the telephones always stop working. Isolation in natural environments such as the woods in The Blair Witch Project (Sanchez and Myrick 1999) provides the same enforced helplessness that is so often a prerequisite for horror (Clasen 2017).

Let us consider the architecture of a haunted house as a classic example of a place that creeps us out because it lacks the reassuring psychological features that we crave.

\section{Why Haunted Houses Creep Us Out}

The haunted house is a time-honored horror setting, and it is not only at the movies that we pay good money to be frightened by them; commercial haunted houses are an integral part of twenty-first-century Halloween theatre, with an estimated 5,000 such attractions operating in the United States each year
(HauntedHouseAssociation.org 2018). While it is true that commercial haunted houses are not "real" haunted houses but rather "scare attractions" that have been artificially engineered to scare us, their design has been inspired by the familiar tropes of horror films as well as by the features associated with the legends surrounding houses reputedly haunted by actual spirits. Thus, I will use the term "haunted house" to refer to both. The discussion of haunted houses below, however, will focus on "real" haunted houses rather than scare attractions.

The cinematic portrayal of haunted houses has remained remarkably consistent across time, and the architects of our annual Halloween spook houses incorporate all of the same bells and whistles (okay-creaks and groans) that we've come to expect. From a psychological point of view, the standard features of haunted houses creep us out because they exploit evolved psychological mechanisms that warn us of potential danger and motivate us to proceed with caution.

Houses that send signals of being haunted give us the creeps not because they pose a clear threat to us, but rather because it is unclear whether or not they represent a threat. Thus, we become momentarily paralyzed as we sharply focus our attention to determine if there is indeed a real danger awaiting us there. This is the psychology behind feeling "creeped out," and it is a reaction that may be useful if it helps you maintain vigilance when threat is uncertain (McAndrew and Koehnke 2016).

The agent detection mechanisms discussed earlier are on full alert in the standard haunted house, and for good reason. Things that activate hypervigilance for malevolent forces (whether natural or supernatural) abound in large, drafty old houses: rattling or creaking sounds in upstairs rooms; the sighing and moaning of wind passing through cracks; ragged curtains fluttering in the breeze; echoes; and cold spots. Consequently, it is very easy to imagine that one is not really alone in such a place. 
The horror and haunted house researcher Margee Kerr (2015) notes that large old buildings full of rotting wood, exposed ductwork, and other structural defects can produce infrasound and make what is already a creepy experience even spookier. This is because of a phenomenon known as "the Hum," which can be produced by a variety of things in the physical world, including drafty old buildings. In a nutshell, the Hum is a sensation that is caused by exposure to low frequency sounds of twenty hertz or less. These sound waves, known as "infrasound," are inaudible to humans but their slight vibrations may still register as an unidentifiable, ambiguous signal that can set off our creep detectors. In some people, the Hum can produce sleeplessness and even nausea. Two British scientists conducted an experiment on the Hum at a concert in London in 2003 (described by Lallanilla 2013). In this experiment, they exposed an unsuspecting crowd to infrasound through loudspeakers, resulting in widespread reports of uneasiness and chills from the concertgoers, and scientists have found the same effects under controlled laboratory conditions (Persinger 2001).

On top of the creepy sounds that set off agency detectors and dread-producing infrasound, haunted houses also tend to limit our opportunities for escape. Research has consistently shown that we need more personal space while seated than while standing, more space when we are in the corner of a room rather than in the center of it, and more space in rooms with low ceilings (McAndrew 1993). We feel uncomfortable when our personal space is violated anywhere, but especially so in situations where we feel as if escape will become difficult. Such feelings of discomfort are symptomatic of the fact that we are constantly — even if unconsciously_scanning our surroundings and assessing our ability to flee if it should become necessary.

Consequently, the typical Hollywood haunted house is our worst nightmare as it makes fleeing difficult. The darkness and confusing layout of the house may cause us to get lost; at the very least, it would slow us down. Escape could further be impeded by hedges, iron fences, or crumbling stairways - all of which feature prominently in haunted houses in movies. Unfortunately, haunted houses also lack "legibility"; most haunted houses make for the bad combination of very low prospect for us, and very high refuge for the creepy-crawly things that are lying in wait to get us. The typical haunted house is large, dark, surrounded by overgrown vegetation, and full of surprising architectural features such as secret rooms and closets under staircases. Attics and basements are also musthave items, and, of course, spider webs, bats, rats, and insects make nice accessories.

One of the most famous real-life haunted houses possesses the aforementioned characteristics in spades. The Winchester Mystery House in San Jose, California is reputed to be the most haunted house in the world and it allegedly houses more than one thousand different ghosts. This house was the inspiration for the movie Winchester (Spierig and Spierig 2018), starring Helen Mirren. This house was originally the home of Sarah Winchester, who was the widow of William Wirt Winchester, the gun-manufacturing magnate. Construction of the house began in 1884 , completely unguided by any sort of coherent building plan, and it continued unabated until 1922. At least part of the construction was driven by the need to repair extensive damage from the 1906 San Francisco earthquake.

Rooms, whimsical architectural features, and different wings and floors were added haphazardly, resulting in a rambling, bizarre puzzle of secret passageways, stairways, and doors that do not go anywhere, and windows with views into other interior rooms. There is even a room constructed specifically for conducting séances. At its peak, the house had over 500 rooms, more than 10,000 windows, and many dozens of fireplaces and stairways.

In short, the Winchester Mystery House is the epitome of illegibility, and it is not surprising that ghosts took up residence there in very short order. 
A recent study (Gray et al. 2018) reveals another reason why dark forbidding places come across as less than hospitable to us. In a series of seven experiments, Gray and his colleagues discovered that people most easily imagine extremely moral, good people and extremely immoral, evil people as having an afterlife, but the types of afterlives they experience are quite different. Specifically, good people are pictured in "transcendent immortality," inhabiting a spiritual paradise such as heaven, or if their spirits remain on Earth, as inhabiting expansive, open places such as mountaintops and deserts. The malevolent spirits of deceased evil-doers, on the other hand, are most easily conceptualized in a "trapped immortality" where they exist in highly circumscribed surroundings such as a particularly dense forest, a haunted house, or even a single room. Given these new data, it is not at all surprising that spiritual presences that we encounter in old houses and other settings that lack legibility scare us rather than comfort us.

In summary, haunted houses provide a treasure trove of things that set off our evolved agent detection mechanisms, and our reactions to them are shadows of how our prehistoric ancestors managed the uncertainty of danger in their own world.

As powerful as architecture alone may be in creating a creepy setting, other features can interact with it in ways that magnify its impact. Specifically, the age of a place, and its association with death or troubled past events can prime us to resolve ambiguity in ways that are guaranteed to creep us out.

\section{The Older the Place, the More Likely It Is to Feel Haunted}

Why should a place that is old, especially if it has a sordid history, be more likely to creep us out?

The answer to this question seems quite simple. If a place has demonstrated a past proclivity for providing unfortunate outcomes for those who have visited it, we take that as a warning and resolve ambiguous feelings about the place by moving in the direction of caution. One of the main reasons why we think that older places are more likely to be haunted is simply because there has been much more time for tragic things to have taken place. Thus, stimuli such as moldy odors, antiquated Victorian or Gothic architecture, wood interiors, and old portraits on the wall reinforce an ambiance of great age and make a place seem creepier.

Most haunted houses have some sort of "legend" associated with them. It usually involves a story about a macabre death or accident. There may even be a history of suicide and murder, as in the famous house in Fall River, Massachusetts, where Lizzie Borden allegedly murdered both of her parents with an ax. A less well-known ax murder house is located in the small town of Villisca, Iowa. In June of 1912, eight people (including six children) were murdered with an ax, and the crime was never solved. The house still stands, and it is widely believed by the locals to be haunted by the ghosts of the children who can be heard laughing, crying, and warning each other to hide.

Assuming that the house is no longer occupied, signs of life suddenly interrupted and frozen in time only amplify the fear factor; remnants of a half-eaten meal on a kitchen table or clothing laid out on a bed waiting for a homeowner who has apparently vanished without warning create a frightening ambiguity about what may have taken place in the house. For example, in Belgium there is an abandoned estate, and it is clear that its residents fled in quite a hurry because many valuable items of furniture dinnerware, artwork, and other personal artifacts were left behind. What makes this seem all the creepier is the fact that after decades of being empty and unattended, no one has looted the place and there is little evidence that very many have even explored it (Enkivillage 2018).

Similarly, the abandoned city of Pripyat in the Ukraine has become the poster child for the creepiness of life frozen in time. This city of 50,000 people was evacuated very quickly 
following the Chernobyl nuclear accident in 1986 and its residents were never allowed to return. All of the clocks in the city are frozen in time at 11:55 and the trappings of interrupted everyday life are everywhere to be seen: toys and schoolbooks lie where they were dropped long ago by children who are now middle-aged people; amusement park rides are seemingly stopped in mid ride; kitchens are full of unwashed dishes. The city is slowly being reclaimed by the surrounding forest and wildlife, and it will eventually be completely unrecognizable as the vibrant place that it once was.

While the empty Belgian estate and the city of Pripyat are not actually all that old, their abandonment and decay convey a sense of the passage of time that confers an aura of creepiness upon them that other locations of similar age do not possess.

Thus, we are more on our guard in settings with ambiguous or even sordid pasts because our agent detection mechanisms are fully engaged when we are there.

\section{Institutions that Once Housed Troubled Populations Are Especially Likely to Seem Haunted}

Sociologist Margee Kerr (2015) has noted that places that isolate people without their consent such as prisons and insane asylums are often considered scary. I would take this one step further and propose that any institution that once housed any "troubled" population of people may become "contaminated" by this association in the minds of imaginative individuals and thereby be believed to more likely to visit trouble upon visitors who dare to explore such places. Again, our brains take advantage of any information that will guide us to a conclusion about the costs or benefits associated with spending time in a place, and such places are very strongly associated with bad stuff. So, it is not surprising to find that prisons, orphanages, and hospitals are ubiquitous on virtually every list of creepy places.
Pennsylvania's Eastern State Penitentiary is a famously creepy place. The prison opened in 1829 and it was one of the first places to experiment with a range of "rehabilitation" techniques such as solitary confinement. It is gigantic, dark, gloomy, and altogether forbidding. In its day, it housed some of the most violent and troubled people in the country. According to Kerr, it has become the most popular American haunted attraction outside of an amusement park, and it runs an annual spooky event known as "Terror Behind the Walls." Other old US prisons, notably the old West Virginia State Penitentiary, have also reopened for business as haunted houses. Similarly, abandoned orphanages and hospitals (especially mental hospitals) are often thought to be inhabited by the suffering ghosts of the tortured souls who once walked their corridors. One of the best known of these is the Pennhurst Asylum in Pennsylvania.

In short, the history of a place provides information that helps us resolve ambiguity about the nature of the emotions that we should experience there, and the places described above have never been happy places.

\section{Places Associated with Death Are Automatically Creepy to Us}

Death is inherently creepy to us because of its ambiguity, and ambiguity is the soil in which horror grows. Very few people know exactly when or how they will die, let alone what happens to them after their death, and religion has been the traditional vehicle for allaying our fears and resolving the uncertainty surrounding death (Bering 2002; McAndrew 2017). And since there was no evolutionary payoff for being able to think of one's self as being dead, we never developed the mental machinery that would make such thinking easy. Hence, the mere act of contemplating death is fraught with confusion and uncertainty, adding to its creepy mystique. By priming thoughts of death, places defined by death quite naturally cause us to become aware 
of our own mortality, which may inspire a sense of urgency in our agent detectors.

The old expression "whistling past the graveyard" reflects the longstanding unease that humans have around places associated with death. Therefore, it should not be surprising to discover that places that have been the scene of a death frequently become haunted places, and these locations are common settings for horror movies and books. The more gruesome and traumatic a death, the more likely it is that the place where it happened becomes tainted by the event. Locations that were the scene of executions, such as the places in town squares where gallows were built or where beheadings occurred, are often linked with ghost stories, as are battlefields and mines where men have traditionally died violent deaths.

In early twentieth-century England, it was widely believed that the spirits of miners who had been killed in previous mine disasters suddenly appeared to warn miners about an impending collapse of the walls around them (Ringwood 1957). In some mines, the legend was passed down with the twist that it was the ghosts of the children of dead miners who delivered the bad news. In almost every mine, beliefs about the ghosts of miners killed in accidents haunting the very spot where they had died were common (Gwyndaf 1994).

College and university campuses where dramatic deaths have occurred are often thought of as haunted, perhaps because deaths that occur in such a young population are by definition unexpected and traumatic. Many, if not most, colleges have at least one resident ghost. Kenyon College in Ohio has a reputation for having one of the most haunted campuses in America. In fact, the place is so full of spirits that the main gates to the campus have come to be known as the "Gates of Hell." An inordinate number of students have died in tragic and unusual ways in the history of the college (Woodyard 1991), and their ghosts haunt the place by rearranging furniture, turning lights on and off, flushing toilets in empty bathrooms, and creating wet footprints in a dance hall that used to be a swimming pool. Other ghosts unscrew light bulbs and jog around the track at night. The most tragic event was a dormitory fire in 1949 that claimed the lives of nine students, and the spirits of the fire victims have reportedly been seen in the halls of the now restored building, visible only from the knees up because the foundation of the rebuilt dorm is roughly ten inches higher than the old one.

Suicides can score extra horror points for the places in which they occur, but the mere occurrence of a suicide does not seem to be enough in and of itself to make a place seem dreadful - the site must possess additional qualities to bestow true creepiness upon the locale. For example, the number one suicide destination in the world is the Golden Gate Bridge in San Francisco, but in spite of the estimated 2,000 suicides that have occurred there since the bridge opened in 1937, most people do not think of the bridge as a creepy place. In the universe of suicide destinations, the clear frontrunner for the title of creepiest suicide venue is the infamous "Suicide Forest” in Japan.

The Aokigahara Jukai forest is a beautiful, dense, 14 square mile patch of vegetation near Mount Fuji, Japan's sacred mountain. It provided the inspiration for the 2016 horror film The Forest (Zada 2016). The place has long been associated with mystical and supernatural phenomena, and in the 1800s it was a popular destination for abandoning elderly people so they could die alone and with dignity in the woods. In fact, it is described in a book with the somber title The Complete Manual of Suicide (Tsurumi 1993) as "the perfect place to die," and copies of this book have been found on the bodies of many suicide victims in the forest.

In spite of its long association with death, it is primarily since it was used by a Japanese novelist in the 1960s as the setting for a story about two lovers who end up killing themselves that it has come to be known as a suicide haven. Suicides are so common there (105 victims in 2003 alone!) that the area is regularly patrolled by police and teams of volunteers who seek to 
save people from themselves or to at least recover the bodies of those whom they could not save. Signs with messages such as "Please consult the police before you decide to die" and "Your life is a precious gift from your parents" are posted throughout the forest in an attempt to deter individuals who may be wavering in their resolve. Some individuals prowl the forest looking for the bodies of the dead so that they might rob them of any valuables that may still be in their possession.

Unlike the Golden Gate Bridge, the forest has all of the trappings essential for being creepy. It is full of densely packed trees, rotting logs, moss, and underbrush, and the lack of legibility in the forest is exacerbated by the fact that compasses do not work there because of the high concentration of magnetic iron in the rocky volcanic soil. Folklore has it that the spirits of people who have killed themselves in the forest call others to the place and then prey upon those who are sad by luring them off the trails, deep into the woods.

Cemeteries and burial grounds in general quickly come to mind when one is asked to think of creepy places. There are, of course, many stories of cemetery ghosts such as the woman who haunts an old cemetery in Alexandria, Virginia. In 1816, a young woman visited the town with her husband. Her face was completely covered with a veil, and no one had a chance to meet her or see her face before she was overcome by a mysterious illness that killed her. The medical staff that treated her agreed to keep her identity confidential, and the husband buried her in the local cemetery all by himself. Consequently, no one ever found out who she was. Her veiled figure has reportedly been seen wandering through the cemetery ever since.

The one thing that seems to really rile up the ghosts in a graveyard is the desecration or disturbing of graves where the dead have finally gotten comfortable. In Owen Davies' (2007) history of English ghosts, a disruption of burial plots by construction projects or body snatching invariably leads to an increase in strange paranormal activity around the graveyard. This, of course, was the premise of the very scary Poltergeist (Hooper 1982) horror movie series. In the original film, an unsuspecting suburban family purchases a home from a greedy land developer who has built new homes on top of a sacred Indian burial ground. The spirits of the dead communicate with the youngest child in the family via the television set and eventually kidnap her by dragging her through a portal in her bedroom closet into the spirit world. Again, it was the disruption of the resting dead rather than their mere proximity that led to all of the trouble.

In summary, places associated with death prime us with thoughts of our own death, placing our agent detection systems on high alert.

\section{The Psychology Behind Why Stories of Haunted Houses and Other Creepy Places Are Self- Perpetuating}

So, why do beliefs in haunted places persist in the enlightened twenty-first century? The answer to this question can be found in the way that humans process and remember information.

It seems as if everyone likes a good haunted house story, and a belief in the veracity of these tales often persists long after the facts of the case reveal them to be little more than a legend. Part of the problem is that once an individual believes that haunted houses are real, even well-intentioned individuals may hoodwink themselves into experiences that genuinely creep them out. In the words of sociologist Christopher Bader, "The first requirement for there being a ghost in the house is someone believing there's a ghost in the house" (Laskow 2018).

Our proclivity for falling into this trap is intimately related to how we have evolved to process sensory input from our environment. Evolutionary success required the development of perceptual systems that accurately reflect what is in our immediate environment, especially when it comes to detecting predators and other dangers. Both speed and accuracy in 
assessing what is out there are important; however, perception is of necessity a trade-off between speed and accuracy. Our cognitive processing system helps soften this necessary trade-off by gambling a bit and quickly recognizing things that are likely to occur in a place, even if there are changes in perspective or we are forced to deal with very sketchy sensory information. For example, if you are driving along a highway and pass a farm, any large dark figure moving in the distance is likely to be quickly recognized as a horse, a cow, or a pig, since these are the stimuli that would be "probable" in that environment. In these situations, the speed of recognition will usually not interfere with accuracy. This is called "top-down processing" by cognitive psychologists who study pattern recognition (McAndrew 1993), as the process is driven by expectations about which objects are likely to be found in a particular setting. In other words, top-down processing causes us to seek specific perceptions before we receive any sensory information at all.

Top-down processing combined with the agent detection mechanisms discussed earlier may explain the tendency to perceive ghosts and other paranormal activity in places that we already believe to be haunted. A fascinating case study of just such a situation has been described by paranormal investigator Benjamin Radford (2008), who was contacted by a terrified woman near Buffalo, New York, in November of 2003. She was completely convinced that her house was haunted by ghosts or at least by some sort of evil spirit. She and her husband were contemplating moving because they could no longer stand the tension of living in a haunted house. They had been in the house about three years, and over time they saw an increase in what they believed to be paranormal activity, such as strange noises, sights, and sensations. The couple even summoned a priest to bless their house, but the haunting continued to get worse.

Radford, who worked for the Committee for the Scientific Investigation of Claims of the
Paranormal in Amherst, New York, agreed to look into the case. He found the husband and wife to be normal, sincere people who were thoroughly frightened and creeped out by what was going on in their home. After a few weeks of experimentation and investigation, he discovered that the couple had inadvertently, but quite literally, haunted their own house. They fed each other's fears by engaging in self-confirming top-down processing guided by expectations. Once they believed that their house was haunted, any ambiguity that they experienced was resolved in the direction that was dictated by their fears, which in this case meant that there were ghosts running wild in the house.

\section{Conclusion}

In summary, the scientific work discussed in this paper suggests that the plots and props of contemporary horror fiction and film are securely anchored to the parts of our unconscious that we have inherited from our prehistoric ancestors. McAndrew and Koehnke (2016) proposed that our reactions to "creepy people" are based upon ambiguity and our lack of confidence about being able to read their intentions; it appears that this theoretical framework might work equally well in helping us understand our reactions to creepy places. I have no concern that a deeper understanding of the inner workings of creepiness might undermine our ability to enjoy horror in fiction, film, and scare attractions, since the stimuli that trigger our reactions bypass (for the most part) the conscious, deliberative part of our cognitive selves where such knowledge resides. So, introducing an air of uncertainty into an antiquarian environment where terrible things have happened before (and may happen again) will always place us on our highest alert, and when combined with hazards that have threatened humans from the dawn of time, will creep us out every time. 


\section{WORKS CITED}

Alcock, John R. 1993. Animal Behavior. 5th ed. Sunderland: Sinauer Associates, Inc.

Appleton, Jay. 1975. The Experience of Landscape. London: John Wiley \& Sons.

Atran, Scott. 2002. In Gods We Trust. New York: Oxford University Press.

Bachelard, Gaston. 1958. The Poetics of Space. Paris: Presses Universitaires de France.

Barrett, H. Clark. 2005. "Adaptations to Predators and Prey." In The Handbook of Evolutionary Psychology, edited by David M. Buss, 20-23. Hoboken: John Wiley \& Sons.

Bering, Jesse. 2002. "Intuitive Conceptions of Dead Agents'Minds: The Natural Foundations of Afterlife Beliefs as Phenomenological Boundary." Journal of Cognition and Culture 2 (4): 263-308. doi:10.1163/15685370260441008.

Blackburn, Farren. 2016. Shut-In. Saint-Denis, France: Europacorps

Botting, Fred. 2015. “Horror Space: Reading House of Leaves." Horror Studies 6 (2): 239-53. doi:10.1386/host.6.2.239_1.

Brown, Steven T. 2018. "Ambient Horror: From Sonic Palimpsests to Haptic Sonority in the Cinema of Kurosawa Kiyoshi." In Japanese Horror and the Transnational Cinema of Sensations. East Asian Popular Culture, edited by Steven T. Brown, 27-84. London: Palgrave-Macmillan.

Busse, Curt. 1980. "Leopard and Lion Predation Upon Chacma Baboons Living in the Moremi Wildlife Reserve." Botswana Notes \& Records 12 (1): 15-21.

Bussing, Ilse M. 2016. “Complicit Bodies: Excessive Sensibilities and Haunted Space." Horror Studies 7: 41-59. doi:10.1386/ host7.1.41_1.

Clasen, Mathias. 2017. Why Horror Seduces. New York: Oxford University Press.

Clasen, Mathias, Jens Kjeldgaard-Christiansen, and John A. Johnson. 2018. “Horror, Personality, and threat Simulation: A Survey on the Psychology of Scary Media." Evolutionary Behavioral Sciences 15 (3): 213-30. doi:10.1037/ ebs0000152.

Coss, Richard G., and Michael Moore. 2002."Precocious Knowledge of Trees as Antipredator Refuge in Preschool Children: An Examination of Aesthetics, Attributive Judgments and Relic Sexual Dinichism." Ecological psychology 14 (4): 181-222. doi:10.1207/S15326969ECO1404_1.

Coss, Richard G., and Michael Penkunas. 2016. "Sex Difference in Choice of Concealed or Exposed Refuge Sites by Preschool Children Viewing a Model Leopard in a Playground Simulation of Antipredator Behavior." International Journal of Psychological Research 9 (2): 8-19. doi:10.21500/20112084.2325.

Davies, Owen. 2007. The Haunted: A Social History of Ghosts. London: Palgrave Macmillan.

De Backer, Charlotte, J. S., Mark Nelissen, Patrick Vyncke, Johan Braeckman, and Francis T. McAndrew. 2007. "Celebrities: From Teachers to Friends. A Test of Two Hypotheses on the Adaptiveness of Celebrity Gossip." Human Nature 18: 334-54. doi:10.1007/s12110-007-9023-z.

Dovey, Kim. (1985). “Home and Homelessness." In Home Environments, edited by Irwin Altman and Carol Werner, 33-64. New York: Plenum Press.

Eliovson, Sima. 1978. "The Japanese Garden."In Humanscape: Environments for People, edited by Stephen Kaplan and Rachel Kaplan, 170-74. North Scituate: Duxbury Press.

enkivillage.com. 10 super creepy places around the world. http://www.enkivillage.com/creepy-places.html. Accessed May 17, 2018.

Fisher, Bonnie. S., and Jack L. Nasar. 1992. "Fear of Crime in Relation to Three Exterior Site Features: Prospect, Refuge, and Escape." Environment and Behavior 24: 35-65

Gray, Kurt, Stephen Anderson, Cameron M. Doyle, Neil Hester, Peter Schmitt, Andrew J. Vonasch, Scott T. Allison, and Joshua Jackson. 2018. “To Be Immortal, Do Good or Evil." Personality and Social Psychology Bulletin 44: 868-80. doi:10.1177/0146167217754068.

Greenbie, Barrie B. 1982."The Landscape of Social Symbols." Landscape Research 7: 2-6. doi:10.1080/01426398208706035.

Gwyndaf, Robin. 1994. The Past in the Present: Folk Beliefs in Welsh Oral Tradition. Fabula 35: 257-58. doi:10.1515/ fabl.1994.35.3-4.226.

HauntedHouseAssociation.org http://www.hauntedhouseassociation.org/haunted_attraction_information. Accessed May 17, 2018. 
Herzog, Thomas R. 1987. "A Cognitive Analysis of Preference for Natural Environments." Landscape Journal 6: 140-52. doi:10.3368/lj.6.2.140.

Herzog, Thomas R, and Gregory A. Smith. 1988. "Danger, Mystery, and Environmental Preference." Environment and Behavior 20 (3): 320-44. doi:10.1177/0013916588203004.

Hester, Randolph. 1979. “A Womb with a View: How Spatial Nostalgia Affects the Designer." Landscape Architecture 69: $475-81 ; 528$

Hooper, Tobe, dir. 1982. Poltergeist. United States: MGM/UA.

Isbell, Lynne A. 1994. "Predation on Primates: Ecological Patterns and Evolutionary Consequences." Evolutionary Anthropology 3: 61-71. doi:10.1002/evan.1360030207.

Kaplan, Rachel, and Stephen Kaplan. 1989. The Experience of Nature: A Psychological Perspective. New York: Cambridge University Press.

Kaplan, Stephen. 1987. "Aesthetics, Affect, and Cognition: Environmental Preference from an Evolutionary Perspective." Environment and Behavior 19: 3-32. doi:10.1177/0013916587191001.

Kerr, Margie, dir. 2015. Scream. United States: Public Affairs.

Kubrick, Stanley. 1980. The Shining. United Kingdom, United States: Warner Bros.

Lallanilla, Marc. 2013, July 25. Mysterious hum driving people around the world crazy. Livescience.com. http://livescience. com/38427-the-hum-mystery-taos-hum.html. Accessed May 17, 2018.

Laskow, Sarah. 2018, August 31. "All It Takes to Create a Ghost Story is a Good Story." Atlas Obscura. https://www. atlasobscura.com/articles/true-ghost-stories-portland-oregon. Accessed August 1, 2019.

Le Saout, Soizic, Jean-Louis Martin, Pierrick Blanchard, Nicolas Cebe, Mark Hewison, Jean-Luc Rames, and Simon Chamaillè-James. 2015. "Seeing a Ghost? Vigilance and its Drivers in a Predator-Free World."Ethology: International Journal of Behavioural Biology 121: 651-60. doi:10.1111/eth.12377.

Li, Chunwang, Xiabo Yang, Yuhua Ding, Linyuan Zhang, Hongxia Fang, Songhua Tang, and Zhigang Jiang. 2011. “Do Père David's Deer Lode Memories of Their Ancestral Predators?" PLOS One 6 (8): e23623. doi:10.1371/journal. pone.0023623.

Martin, Luther H. 2014. Deep History, Secular Theory: Historical and Scientific Studies of Religion. Berlin: De Gruyter. McAndrew, Francis. T. 1993. Environmental Psychology. Pacific Grove: Brooks/Cole.

_ 1998. "The Measurement of 'Rootedness' and the Prediction of Attachment to Home-Towns in College Students." Journal of Environmental Psychology 18: 409-17. doi:10.1006/jevp.1998.0078.

—.2017, October 25. "How the God You Worship Influences the Ghosts You See." The Conversation. https://theconversation.com/how-the-god-you-worship-influences-the-ghosts-you-see-84163. Accessed July 27, 2019.

McAndrew, Francis T., and Sara S. Koehnke. 2016. "On the Nature of Creepiness." New Ideas in Psychology 43: 10-15. doi:10.1016/j.newideapsych.2016.03.003.

Nickell, Joe. 2012. The Science of Ghosts. Amherst, NY: Prometheus Books.

2012. "Incarcerated Ghosts: Haunted Dungeons, Prisons, and Jails." In The Science of Ghosts, edited by Joe Nickell, 133-39. Amherst, NY: Prometheus Books.

Orrock, John L. 2010. “When the Ghost of Predation has Passed: Do Rodents from Islands with and without Fox Predators Exhibit Aversion to Fox Cues?" Ethology: International Journal of Behavioural Biology 116: 338-45. doi:10.1111/ j.1439-0310.2010.01740.x.

Persinger, Michael. A. 2001. "The Neuropsychiatry of Paranormal Experiences." Journal of Neuropsychiatry and Clinical Neuroscience 13: 515-23. doi:10.1176/jnp.13.4.515.

Proshansky, Harold M., Abbe K. Fabian, and Robert Kaminoff. 1983. "Place Identity: Physical World Socialization on the Self." Journal of Environmental Psychology 3: 57-83. doi:10.1016/S0272-4944(83)80021-8.

Radford, Benjamin. 2008. "How to'Haunt' a House." Skeptical Inquirer 32: 31-36.

Ramakrishnan, Uma, and Richard G. Coss. 2001. "Strategies Used by Bonnet Macaques (Macaca radiata) to Reduce Predation While Sleeping." Primates 42 (3): 193-206. doi:10.1007/BF02629636.

Ringwood, Margaret. 1957. "Some Customs and Beliefs of Durham Miners." Folklore 68: 423-24.

Sanchez, Eduardo, and Daniel Myrick, dirs. 1999. The Blair Witch Project. United States: Lionsgate Films.

Smith, David L. 2016, September 19. A Theory of Creepiness. Aeon Magazine, https://aeon.co/essays/what-makesclowns-vampires-and-severed-hands-creepy. Accessed August 20, 2020. 
Smith, Jonathan Z. 1987. To Take Place: Toward Theory in Ritual. Chicago: University of Chicago Press.

Sommer, Robert. 1969. Personal Space: The Behavioral Basis of Design. Englewood Cliffs: Prentice-Hall, Inc.

Spierig, Michael, and Peter Spierig, dirs. 2018. Winchester. United States: Lionsgate Films.

Spörrle, Matthias, and Jennifer Stich. 2010. "Sleeping in Safe Places: An Experimental Investigation of Human Sleeping

Place preferences from an Evolutionary Perspective." Evolutionary Psychology 8 (3): 405-19. doi:10.1177/147470491000800308.

Suedfeld, Peter. 1987. "Extreme and Unusual Environments." Handbook of Environmental Psychology, edited by Daniel Stokols and Irwin Altman, 348-68. New York: John Wiley \& Sons.

Tsurumi, Wataru. 1993. The Complete Manual of Suicide. Tokyo: Ota Shuppan.

Tuan, Yi-Fu. 1974. Topophilia. New York: Columbia University Press.

1977. Space and Place. Minneapolis: University of Minnesota Press.

Watt, Margo C., Rebecca A. Maitland, and Catherine E. Gallagher. 2017."A Case of the Heeby Jeebies: An Examination of Intuitive Judgments of Creepiness." Canadian Journal of Behavioural Science, 49 (1): 58-69. doi:10.1037/ cbs0000066.

Woodyard, Chris. 1991. Haunted Ohio: Ghostly Tales from the Buckeye State. Dayton: Kestrel Publications.

Zada, Jason. 2016. The Forest. Universal City: Gramercy Pictures.

Zemeckis, Robert, dir. 2000. Cast Away. United States: 20th Century Fox. 
